\title{
Evaluation of the use of monopolar diathermy in control of cystic artery during laparoscopic cholecystectomy/review of 142cases in Al-Imamain-Al-Kadhumienmedical city
}

\author{
Dr. Sudad Salman Ahmed Al-Bassam, Dr. Osama Al-Abid \\ ( FICMS, CABS, IMRCS +FEBS) department of surgery / Al-Nahrain medical college \\ ( FICMS ,FRCS) , department of surgery / Al-Imamein Al-kadhumain medical city.
}

\begin{abstract}
:
Background: different methods like clipping, ligation and cauterization were used to control the cystic artery during laparoscopic cholecystectomy, each of them has its own advantages and disadvantages in this prospective study we focused on the use of monopolar diathermy to control the cystic artery.

Patient and methods: prospective study of 142 case of laparoscopic cholecystectomy due to gall stones non of them was complicated, done by 2 surgeons in Al-Imamain Al-Kadhumien medical city basically we tried to control the cystic artery by monopolar diathermy of its small branches adjacent to the wall of gall bladder without need to dissection of calot's triangle to control the main cystic artery.

Results :the cystic artery (all varieties)and its branches was found in calot's triangle, effective control of the artery by the cautery alone was possible in 103 cases while classical clipping needed in 39 cases.

Conclusion :careful use of diathermy is a safe and efficient method to control the cystic artery during laparoscopic cholecystectomy.
\end{abstract}

Key words: laparoscopic cholecystectomy, monopolar diathermy .

\section{Introduction}

Laparoscopic cholecystectomy is now the golden slandered method for removal of gall bladder due to gall stones and other different pathologies ${ }^{(1)}$, the cystic artery can be controlled in different ways according to

1 - Its size

2- Surgeon experience

3- Availability of instruments

4- Clarity of calot's triangle anatomy.

This can be achieved by:

1- Surgical clips

2- Ligation

3- Use of harmonic knife

4- Mono-polar diathermy ${ }^{(2)}$

A good knowledge of the anatomy of calot's triangle is very important for both classical and laparoscopic cholecystectomy ${ }^{(3)}$.

Calot's triangle or recently called hepato-biliary triangle is the area bordered by the cystic duct, common hepatic duct and the lower edge of the liver.

The great variety of anatomical courses of the cystic artery might create problems with proper recognition and dissection of structures leading to injuries to the cystic artery or bile ducts ${ }^{(4)}$.

Different anatomical and surgical studies described classification of cystic artery origin and course as follow

Group one: originate from the right hepatic artery and courses within hepato-biliary triangle ranging from 85$96 \%$ of cases. Subdivided into

1 -single artery takes its classical course.

2-double cystic arteries.

Group two: the cystic artery originating outside calot's triangle from gastro duodenal artery, right hepatic artery, liver parenchyma, or left hepatic artery.

Group three: the gall bladder supplied by two arteries one originating inside and one originating outside calot's triangle ${ }^{(5)}$.

Groups two and 3 were not seen in our study. 


\section{Patients and methods:}

This prospective study was done in department of surgery in Al -Imamain-Al-kadhimein medical city/ Baghdad Iraq, started at February 2012, it was approved by the committee of medical ethical values in AlNahrain Medical College. regular consents were taken from all patients with verbal explanation of the idea and the technique of the study, all patients have symptomatic gall stones with no complications or abnormalities of liver or biliary tree (checked by sonographic examination); surgeons participated in this study had performed at least 150 successful laparoscopic cholecystectomy who are also experts in classic biliary surgery.

All operations were done under general anesthesia, the patients placed in supine, crucifix, reverse trendelenburg position, four trocar ports were used after sterilization of anterior abdominal wall. In all operations the stomach was emptied by means of naso gastric tube aspiration, dissection of omental adhesions with the liver and well identification of the pathway of cystic duct and artery, in majority of cases the cystic duct was clipped before controlling the cystic artery, in 34 cases the lymph node of Lund needed to be removed or dissected before the control of the cystic artery. The cystic artery was controlled by either titanium clips or monopolar diathermy with short bursts very near to the gall bladder wall depending on the size and number of the arteries. The gall bladder was dissected from its bed in the liver in retrograde manner by electrosurgical hook and the bleeding spots were controlled by spatula. In all cases (except two) the gall bladder was removed through the epigastric port. Sub hepatic tube drain was passed from lateral $5 \mathrm{~mm}$ port in all cases were the cystic artery is controlled by mean of electro cautery without use of titanium clip.

All the data about the control of the cystic artery (size, relation to calot's triangle, type of the control) was recorded immediately after the operation. The patients remained in the hospital for 2 days post operation, the drain was removed before discharge, and the patient was instructed to return back after one month for sonographic examination of the abdomen to evaluate for sub hepatic collection ${ }^{(6)}$.

\section{Results:}

The cystic artery was identified in 124 cases out of 142 cases operated upon (87\%) in this study

- The male to female ratio was approximately $1: 4 ; 27$ male (19.1\%) and 115 female ( $80.98 \%)$.

- In the 27 males 7 patients ( $4.92 \%)$ : the artery needed to be controlled by cautery and in $20(14.08 \%)$ patients the artery needed to be controlled by clipping of the artery ; 115 female ( in 96 patients (67.6\%)the artery controlled by cautery while in 19 patients(13.38) the artery controlled by clipping ).

- Age: the range of patient's age was between (25-70) years .

- Co-morbidity : Diabetes mellitus ( type one and type two) was found in 11 patients and hypertension in 16 patients but had no effect on the final outcome.

- All arteries( the cystic artery in all patients ) were found in calot's triangle.

- Single artery found in $102(82.2 \%)$ cases while 2 arteries found in 22 cases ( $17.8 \%)$

- Operative time: mean operative time for clipping was $48 \mathrm{~min}$, while it was $40 \mathrm{~min}$ when cautery was used.

- Drains collected less than $50 \mathrm{cc}$ in both male and female patients and were used in the 103 cases controlled by diathermy.

- Cautery used in 103 cases ( $72.5 \%)$ while clipping used in 39 cases $(18.5 \%)$

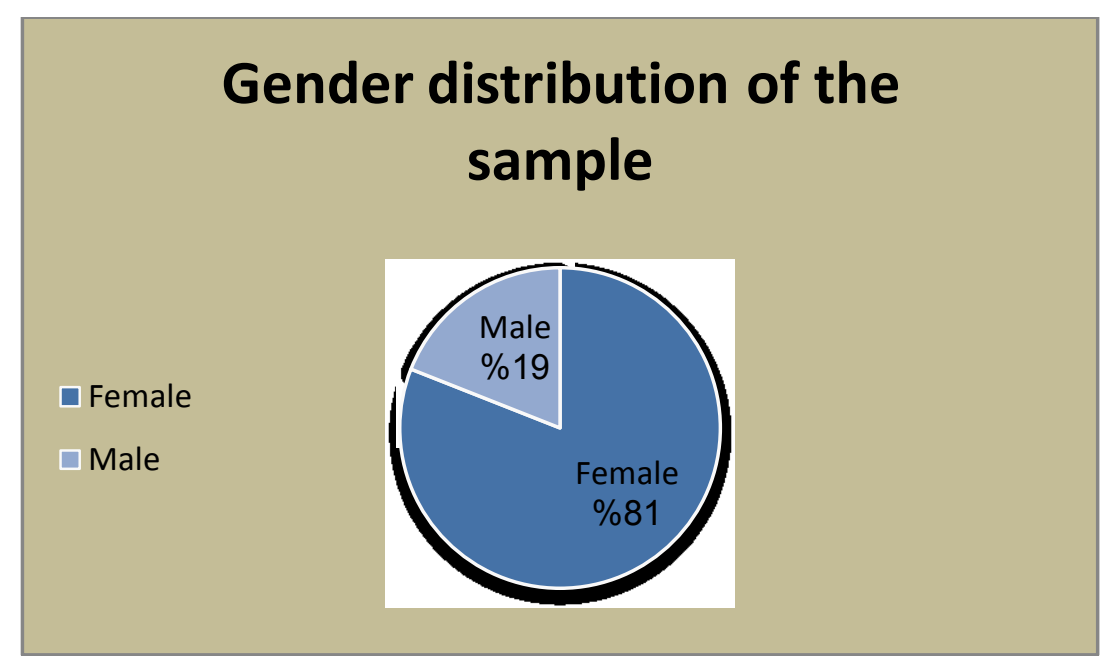



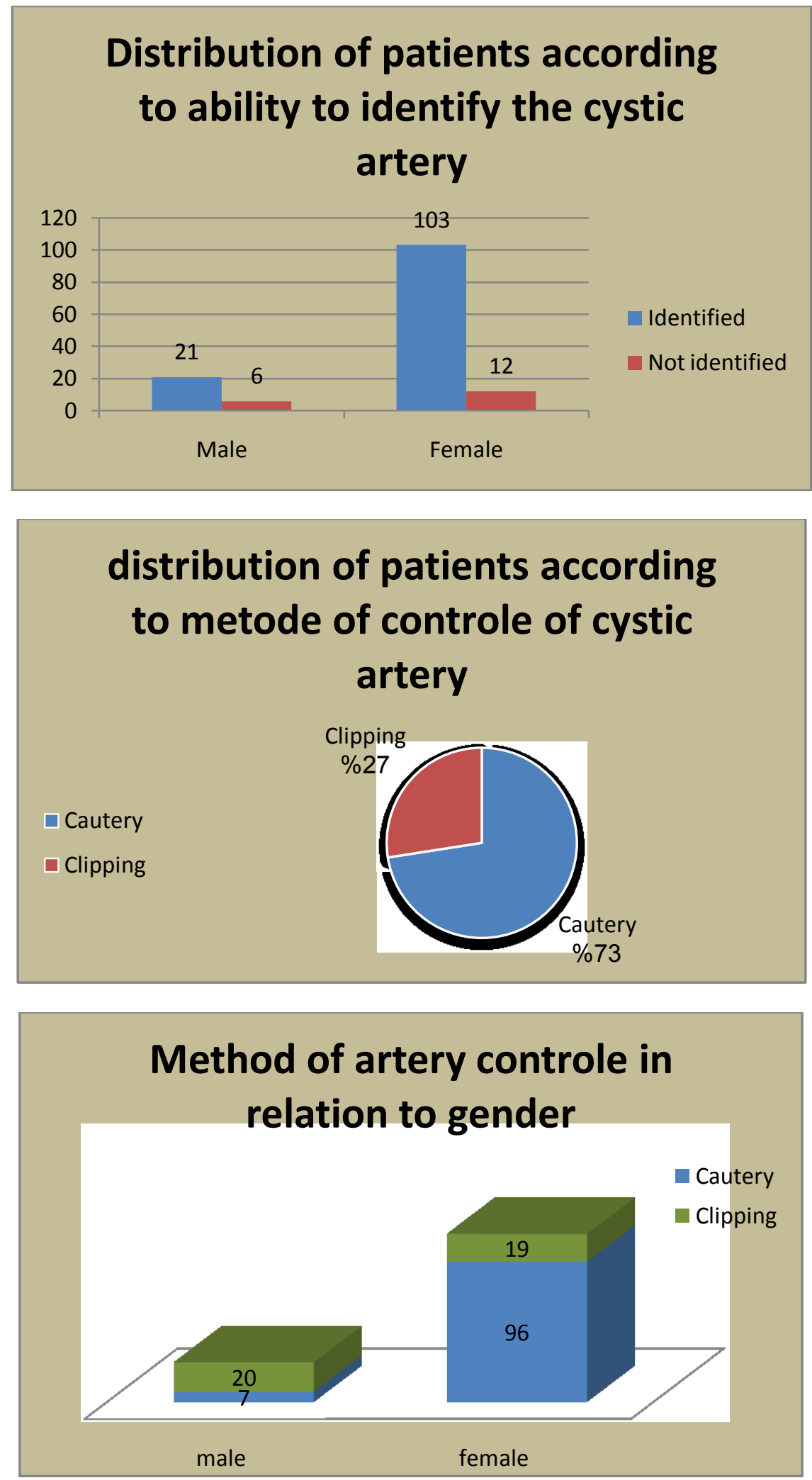

IV. Discussion:

The anatomic variations around and in the calot's triangle are frequent and variable especially those related to cystic artery which are based on its origin, location in the triangle, number of branches ${ }^{(7)}$.

The cystic artery could be located in 124 cases (87\%) in this study (21 male patients and 103 female patients). un identified artery may be due to very small artery specially in fatty calot's triangle or unrecognized variant of cystic artery for example that running along cystic duct and could be clipped and divided together with the duct 
Suzuki et al ${ }^{(8)}$, a cystic artery originating from the bed of gall bladder is another variant. The cystic artery was identified inside the calot's triangle in $100 \%$ of the 124 cases with identified cystic artery. Single artery was found in 102patients, while two arteries are controlled in 22 patients, the surgeon should separately control these branches when the dissection is very close to the gall bladder. katri et al..$^{(9)}$

Although the safety of using electro cautery alone to control the cystic artery has been questioned for the fear that it may not be adequate to seal the artery or may cause biliary injury ( the study.

Cimmino et al). ${ }^{(10)}$ there were neither operative nor postoperative bleeding complications and no bile duct injury as well, this agree with katri et al, this was achieved by careful dissection and good visualization of structures in calot, $\mathrm{s}$ triangle.

Injury due to electro-cautery can be avoided by taking simple precautions like avoiding diathermy near metal clips on the cystic duct and staying close to the gall bladder wall during dissection and control of the cystic artery, preferably lateral to the cystic lymph node( Ramirez-Flores et al $)^{(11)}$.

It's important that always short bursts of a minimal amounts of energy required to secure homeostasis should be used. In our study we found that the careful use of electro cautery to control the cystic artery has the advantage of shorter operative time, we also used drainage of the operative field for monitoring and avoiding the risk of missed hemorrhage ${ }^{(12)}$.

In conclusion, electro cautery is safe and effective for control of the cystic artery during laparoscopic cholecystectomy. Neither bleeding nor bile duct injury was encountered throughout study period; cautery should be applied very close to the gall bladder preferably lateral to the cystic lymph node ${ }^{(13)}$.

\section{References:}

[1]. Hü scher CG, Lirici MM, Di Paola M, Crafa F, Napolitano C,Mereu A, Recher A, Corradi A, Amini M. Laparoscopic cholecystectomy by ultrasonic dissection without cystic duct and artery ligature. SurgEndosc 2003; 17:442-451.

[2]. Bessa SS, Al-Fayoumi TA, Katri KM, Awad AT. Clip less laparoscopic cholecystectomy by ultrasonic dissection. JLaparo endosc AdvSurg Tech a 2008; 18:593-598.

[3]. Kandil T, El Nakeeb A, El Hefnawy E. Comparative study between clip less laparoscopic cholecystectomy by harmonic scalpel versus conventional method: A prospective randomized study. J Gastro intest Surg 2010; 14:323-328.

[4]. Lichten JB, Reid JJ, Zahalsky MP, Friedman RL .Laparoscopic cholecystectomy in the new millennium.SurgEndosc2001; 15:867872 .

[5]. Grace PA, Quereshi A, Coleman J, Keane R, McEntee G, BroeP, Osborne H, Bouchier-Hayes D. Reduced post operative hospitalization after laparoscopic cholecystectomy. Br J Surg1991; 78:160-162.

[6]. Targarona EM, Marco C, Balague C, Rodriguez J, Cugat E,Hoyuela C, Veloso E, Trias M. How, when, and why bile duct injury occurs.A comparison between open and laparoscopic cholecystectomy .SurgEndosc 1998; 12:322-326.

[7]. Strasberg SM, Hertl M, Soper NJ. An analysis of the problemof biliary injury during laparoscopic cholecystectomy. J AmCollSurg 1995; 180:101-125.

[8]. Suzuki M, Akaishi S, Rikiyama T, Naitoh T, Rahman MM,Matsuno S. Laparoscopic cholecystectomy, Calot's triangle ,and variations in cystic arterial supply. SurgEndosc 2000;14:141-144.

[9]. Khaled M. Katri, Samer S. Bessa, Galal Abou Elnagah, and El-Saed A. El-Kayal.Journal of Laparo endoscopic\& Advanced Surgical Techniques. July/August 2012, 22(6): 557-560.

[10]. Cimmino PT, Boccheti T, Izzo L. Anatomo-surgical considerations in laparoscopic cholecystectomy [in Italian]. G Chir1992; 13:149-151.

[11]. Ramirez-Flores R. A new anatomic guide for safe ligation of the cystic artery .Surg Gynecol Obstet 1955; 100:633-635.

[12]. Balija M, Huis M, Nikolic V, Stulhofer M. Laparoscopic visualization of the cystic artery anatomy. World J Surg1999; 23:703-707.

[13]. Ding YM, Wang B, Wang WX, Wang P, Yan JS. New classification of the anatomic variations of cystic artery during laparoscopic cholecystectomy. World J Gastro enterology 2007;13:5629-5634. 